\title{
Net Zero Energy for Industrial and Commercial Microgrids: Approaches and Challenges ${ }^{\dagger}$
}

\author{
Filipe Bandeiras ${ }^{1}$, Mário Gomes ${ }^{2, *}$, Paulo Coelho ${ }^{2}$ and José Fernandes ${ }^{1}$ \\ 1 Instituto Politécnico de Tomar (IPT), 2300-313 Tomar, Portugal; aluno17804@ipt.pt (F.B.); \\ josefern@ipt.pt (J.F.) \\ 2 Ci2-Smart Cities Research Center-IPT, 2300-313 Tomar, Portugal; pcoelho@ipt.pt \\ * Correspondence: mgomes@ipt.pt \\ † Presented at the 2nd International Research Conference on Sustainable Energy, Engineering, Materials and \\ Environment (IRCSEEME), Mieres, Spain, 25-27 July 2018.
}

Published: 2 November 2018

\begin{abstract}
This paper addresses the concept of net zero energy and net metering in efficient buildings in order to assist in the study and development of future microgrids for buildings with annual zero energy consumption. There are several definitions for zero energy buildings available in the literature with a distinct set of project goals and interests, but this work is focused on the definition that accounts for energy losses by converting each energy type to source energy. Finally, a case study is presented to evaluate whether four distinct all-electric buildings can achieve annual zero energy by deploying on-site renewable sources within their site boundary.
\end{abstract}

Keywords: net zero energy; net metering; renewable energy; efficient buildings; microgrids

\section{Introduction}

The building sector is a major contributor to the global energy consumption and carbon emissions [1]. Minimizing the energy consumption and carbon footprint of industrial, commercial and residential buildings has become essential to meet environmental aims and reduce the use of fossil fuels for power generation. Needless to say, this can be achieved through energy efficiency and on-site renewable sources to avoid imported energy from conventional energy sources. The integration of microgrids (MG) also plays an important role in the building sector and constitutes a great opportunity towards achieving zero energy in efficient buildings. Besides being an important asset to help mitigate the environmental impact from the use of fossil fuels, MGs also significantly increase the reliability and quality of the power supplied to the loads without disturbances and interruptions. Different approaches for net zero energy have been described in the literature. However, a common understanding of zero energy buildings (ZEB) is still lacking [2].

\section{Zero energy Buildings}

According to [3], a ZEB is an energy efficient building where, on a source energy basis, the actual annual delivered energy is less than or equal to the on-site renewable exported energy. In other words, a ZEB aims to reduce the use of non-renewable energy in the building sector by implementing energy efficiency measures and producing enough renewable energy to meet or exceed its annual energy consumption. The site boundary can be larger than the building footprint and it is the only area available to deploy renewable energy sources (RES) for on-site energy production [4]. There are several definitions for net ZEBs in the literature that are strongly dependent on the project goals. These definitions take into account different interests and goals established by the building owners such as the amount of energy accounted for at the source or at the site, as well as energy costs and 
environmental concerns associated with the use of fossil fuels. Based on these interests, a building can be defined as site ZEB, source ZEB, cost ZEB and emissions ZEB [4]. Each approach to define ZEBs is summarized in Table 1. MGs provide the ability to safely integrate RES and distributed generation (DG) units into the building sector, enabling control and coordination of the available resources, and thus allowing building owners to correctly manage their energy consumption and increase overall building efficiency. This can be particularly important in cost ZEBs, since MGs can also contribute to a significant reduction in energy costs.

Table 1. Definition approaches for ZEBs.

\begin{tabular}{|c|c|c|c|c|}
\hline & Easier to Implement & Easier to Achieve & Equates Fuel Types & Conversion Factors \\
\hline Site ZEB ${ }^{1}$ & $\checkmark$ & $x$ & $x$ & $x$ \\
\hline Source ZEB ${ }^{2}$ & $x$ & $\checkmark$ & $\checkmark$ & $\checkmark$ \\
\hline Cost ZEB ${ }^{3}$ & $\checkmark$ & $x$ & $\checkmark$ & $x$ \\
\hline Emission ZEB ${ }^{4}$ & $x$ & $\checkmark$ & $\checkmark$ & $\checkmark$ \\
\hline
\end{tabular}

\section{Net Metering}

Net metering is a billing system that consists of a bi-directional meter, enabling customers to be credited for the excess electricity they feed into the utility grid [5]. This allows the customer to take advantage of the credits gained and import electricity from the utility grid during periods when local generation is at a minimum [6]. Net metering policies vary by region and country, which may denote how much the credits are worth. Cost ZEBs require a net metering agreement that allows the customers to be credited at avoided generation rates. Even though MGs are well suited for net metering, they are often excluded from most policies because only a single customer is eligible for net metering and MGs usually involve multiple customers [7]. However in the USA, Pennsylvania allows net metering in renewable installations up to $5 \mathrm{MW}$ for MGs and Connecticut applies virtual net metering that allows each municipal customer to host up to 5 non-municipal accounts in critical facilities connected to a MG. Virtual net metering is a slightly different variation in which the excess electricity credits are applied to the utility account, allowing generation in one location to offset electricity costs at another location [8]. This overcomes problems regarding DG systems in buildings with multiple occupants [9]. Since MGs can also integrate non-renewable sources, net metering is only applied in MGs containing exclusively RES and clean generators.

\section{Energy Balance}

The energy balance is determined from the balance between delivered and exported on-site renewable energy or between load and generation. The demand is the sum of all delivered energy to the building and the supply is the sum of all exported energy, both can be determined by summing each energy type multiplied by the respective source energy conversion factor. This takes into account the energy losses since the extraction of primary fuels. Buildings can be defined as ZEB if their annual energy balance is less than or equal to zero $\left(E_{\text {balance }} \leq 0\right)$ [3], given by (1):

$$
E_{\text {balance }}=E_{\text {demand }}-E_{\text {supply }}=\underbrace{\sum_{i}\left(E_{\text {del,i }} \times r_{\text {del, }}\right)}_{\text {Demand }}-\underbrace{\sum_{i}\left(E_{\text {exp }, i} \times r_{\text {exp }, i}\right)}_{\text {Supply }},
$$

where $E_{d e l, i}$ and $E_{\text {exp,i }}$ are the delivered energy and exported on-site renewable energy for an energy type $i$, respectively. And $r_{d e l, i}$ and $r_{\text {exp,i }}$ are the source energy conversion factor for the delivered and exported energy type $i$, respectively. 


\section{Case Study}

This section presents a case study of four enterprises to evaluate whether these all-electric industrial and commercial buildings can achieve annual zero energy by deploying on-site renewable sources within the site boundary. The enterprises under study include a flour mill, a quarry, an abrasives production plant and a large hypermarket. In order to evaluate each building, this study uses an optimization algorithm to determine the number of photovoltaic (PV) panels and wind turbines (WT) necessary to achieve zero energy and at the same time minimize the implementation cost of these energy sources. To this end, the algorithm was developed using the function "linprog" in Matlab which allows finding the optimal solution for a specific problem defined by inequality constraints, equality constraints and boundaries. The objective function for this problem is given by (2) in Table A1 in Appendix A. The algorithm is forced to prioritize the lower cost of PV panels and WTs, thus avoiding power imported from the grid which is associated to a higher cost. This function is subjected to the inequality constraints given by (3) and limited to upper and down boundaries given by (4) in Table A1. Finally, the equality constraint is given by the zero energy balance formula (5) also listed in Table A1. This allows the algorithm to determine the number of PV panels and WTs according to the zero energy balance, in which supply equals demand. The algorithm was used for each building with the location data and the technical specifications of PV panels and WTs. The results in Table A1 show that achieving zero energy in all-electric industrial and commercial buildings is not an easy task, especially in buildings with great power consumption and no wide open areas. Only the abrasives manufacturing plant and the quarry are able to achieve zero energy, as shown in Table A1. The annual on-site generation in these two enterprises exceeds the annual consumption. In any case, the number of units could be significantly reduced by decreasing power consumption, implementing less conventional PV panels or by including banks of batteries to store the excess generated electricity. Adopting energy efficiency measures and considering net metering can be essential to achieve net zero energy. The importance of net metering reflects in the ability of each customer to store their excess generated electricity in the grid, so it can be used during a month of poor solar radiation or weak wind. This is favourable, since it is not economically viable to store electricity for long time periods and important when integrating non-dispatchable energy sources.

\section{Conclusions}

This paper briefly addressed the concept of zero energy in buildings, focusing on the most common definition approach available for ZEBs. In addition, it also addressed the importance of net metering structures in ZEBs and their possible integration into MG systems. The study carried out in this paper addressed four distinct enterprises and their ability to achieve the status of ZEB. An algorithm was developed in Matlab to evaluate whether these enterprises could reach annual zero energy. As expected, the results concluded that achieving zero energy in industrial and commercial buildings is not an easy task and may not be possible without implementing energy efficiency or any means of storing excess energy generated from on-site renewable sources. Net metering is suggested to help buildings achieve annual zero energy without investing in expensive energy storage systems. The subject addressed in this paper is in desperate need of standardization and common understanding of its concept. More efforts and developments should be made towards the environmental impact of energy intensive buildings and enhancement of future MGs.

Author Contributions: This paper was a collaborative effort among all authors: F.B. and M.G. conceived and designed the net zero energy optimization model; F.B. performed the simulations; M.G., P.C. and J.F. analyzed the data; All the authors participated in the discussion of the results; F.B. wrote the paper and the rest of the authors reviewed it.

Acknowledgments: This work was partially supported by the Portuguese Foundation for Science and Technology (FCT) and by PIDDAC, under the research project INDuGRID, ERANETLAC/0006/2014.

Conflicts of Interest: The authors declare no conflict of interest. The founding sponsors had no role in the design of the study; in the collection, analyses, or interpretation of data; in the writing of the manuscript, and in the decision to publish the results. 


\section{Appendix A}

Table A1. Case study formulation and results for achieving zero energy in all-electric buildings.

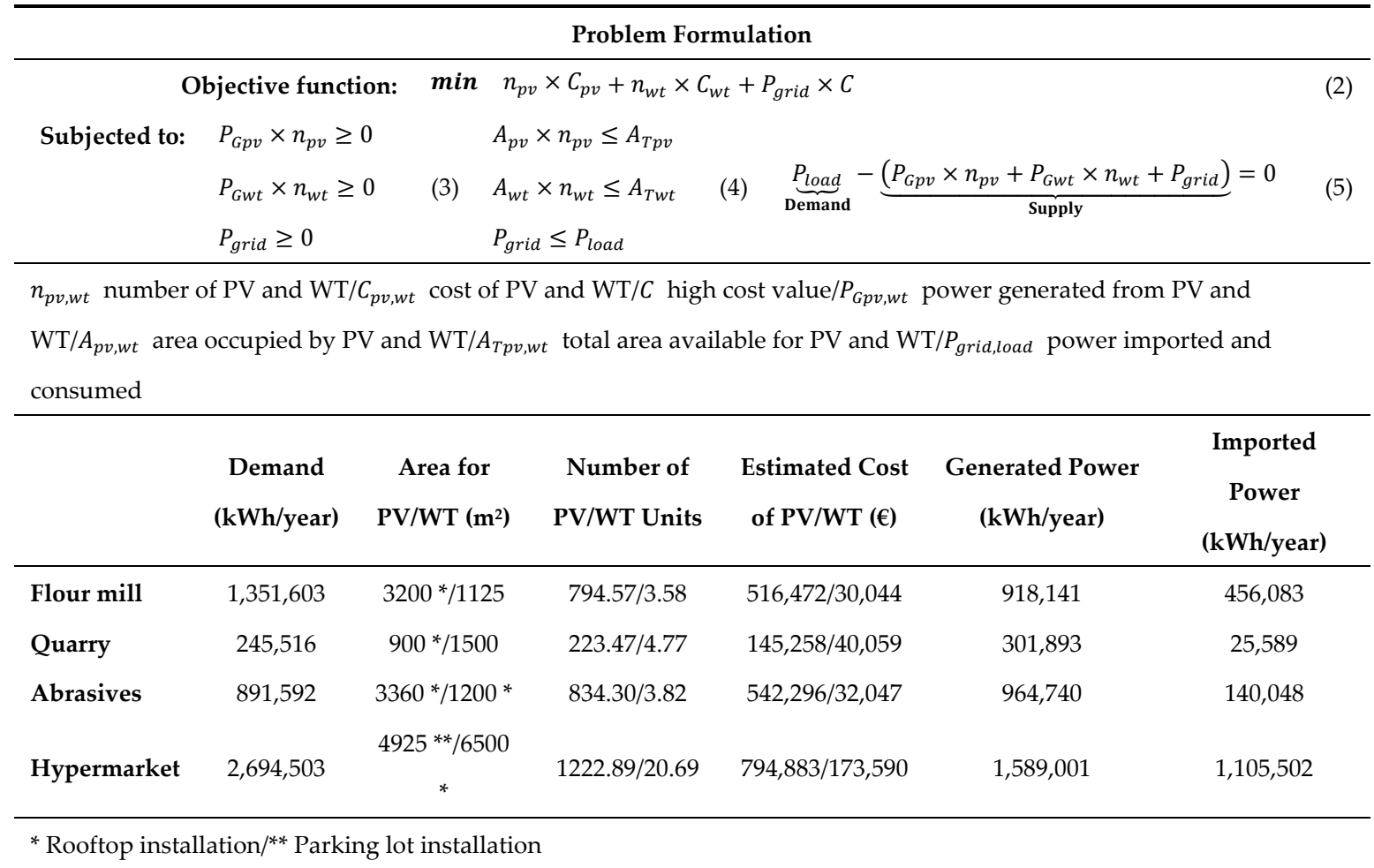

\section{References}

1. Cao, X.; Dai, X.; Liu, J. Building energy consumption status worldwide and the state-of-the-art technologies for zero-energy buildings during the past decade. Energy Build. 2016, 128, 198-213.

2. Marszal, A.; Heiselberg, P. A Literature Review of Zero Energy Buildings (ZEB) Definitions; Aalborg University: Aalborg, Denmark, 2009.

3. U.S. Department of Energy. A Common Definition for Zero Energy Buildings. June 2015. Available online: https://energy.gov/sites/prod/files/2015/09/f26/bto_common_definition_zero_energy_buildings_093015.p df (accessed on 21 September 2017).

4. Torcellini, P.; Pless, S.; Deru, M.; Crawley, D. Zero Energy Buildings: A Critical Look at the Definition; National Renewable Energy Laboratory (NREL): 2006. Available online: https://www.nrel.gov/docs/fy06osti/39833.pdf (accessed on 21 September 2017).

5. Edison Electric Institute. Solar Energy and Net Metering. January 2016. Available online: http://www.eei.org/issuesandpolicy/generation/NetMetering/Documents/Straight\%20Talk\%20About\%20 Net\%20Metering.pdf (accessed on 15 January 2018).

6. Net Metering. Policy Interv. 2012, 5. Available online: http://mnre.gov.in/file-manager/akshay-urja/januaryfebruary-2012/EN/44-45.pdf (accessed on 22 September 2017).

7. Microgrids: An Assessment of the Value, Opportunities, and Barriers to Deployment in New York State; New York State Energy Research and Development Authority (NYSERDA): Albany, NY, USA, 2010.

8. Beavers, D.; McGuckin, J.; Sweet, E. Community Shared Solar: Review and Recommendations for Massachusetts Models; Massachusetts Department of Energy Resources (DOER): 2013. Available online: https://www.mass.gov/files/documents/2016/08/nv/community-shared-solar-model-frameworks032813.pdf (accessed on 26 June 2018). 
9. Sanders, R.G.; Milford, L. Clean Energy for Resilient Communities: Expanding Solar Generation in Baltimore's Low-Income Neighborhoods; Clean Energy Group: 2014. Available online: https://www.cleanegroup.org/wpcontent/uploads/Clean-Energy-for-Resilient-Communities-Summary-Feb2014.pdf (accessed on 26 June 2018). (CC BY) license (http://creativecommons.org/licenses/by/4.0/). 